\title{
ORIGINAL ARTICLE \\ Demographic and clinical characteristics of patients with spinal cord injury: a single hospital-based study
}

\author{
B Zárate-Kalfópulos ${ }^{1}$, A Jiménez-González ${ }^{1}$, A Reyes-Sánchez ${ }^{2}$, R Robles-Ortiz ${ }^{1}$, EE Cabrera-Aldana ${ }^{1}$ and \\ LM Rosales-Olivarez ${ }^{1}$
}

Study design: Retrospective study.

Objectives: To evaluate the demographic and clinical characteristics of patients diagnosed with spinal cord injury (SCl) admitted to a single center.

Setting: Single center study, México.

Methods: This study reviewed 433 patients with SCI. Data were extracted from medical records and retrospectively reviewed.

Results: A total of 433 patients with a diagnosis of SCl were included in the analysis. Of these, 346 (79.9\%) had traumatic SCI (TSCl) and $87(20.1 \%)$ had non-traumatic SCI (NTSCI). The principal causes of traumatic TSCl were motor vehicle accidents in 150 patients (43.4\%), falls in 107 patients (30.9\%) and a result of firearms in 58 patients (16.8\%). Tumoral cord compression was the main cause of $\mathrm{NTSCl}$ in 50 patients (57.4\%), followed by degenerative disease-causing myelopathy in 17 patients (19.5\%). The proportion of patients affected with NTSCI was significantly lower, 29.9 vs $79.1 \%(P=0.0001)$, the age of patients was higher 53.9 vs 37.8 $(P<0.002)$ and $\mathrm{SCl}$ was less severe, AIS D 41.33 vs $9.5 \%(P=0.0001)$ compared with the TSCl group.

Conclusions: The demographic profiles of patients with TSCI and NTSCI differ in terms of proportion of total SCls, patient age, male: female ratio and incomplete vs complete injury. The most common etiology of $\mathrm{TSCl}$ was motor vehicle accidents (43.4\%), and neurological lesions were complete in $62.7 \%$ of patients. The most common etiology of NTSCI was tumoral spinal lesions (57.4\%), and lesions were incomplete in $75.8 \%$ of patients.

Spinal Cord (2016) 54, 1016-1019; doi:10.1038/sc.2016.41; published online 12 April 2016

\section{INTRODUCTION}

Spinal cord lesions can lead to severe functional and psychosocial problems. Spinal cord lesions are a devastating condition. Incidence varies between countries with global annual estimate of 15-40 cases per million. ${ }^{1}$ Within the entire population of patients with spinal cord injury (SCI), traumatic SCI (TSCI) accounts for the largest proportion. $^{2}$ TSCI is more common in males $(82.8 \%$ of cases occurring in males) and occurs at a mean age of 32.4 years. The two leading causes of TSCI in developing countries are motor vehicle accidents $(41.4 \%)$ and falls $(34.9 \%)$. Complete injuries are more common than incomplete injuries ( 56.5 vs $43 \%$, respectively). ${ }^{2-4}$ Nontraumatic SCI (NTSCI) comprises any damage to the spinal cord that has not been caused by a major trauma. Current data suggest that the leading causes of NTSCI are neoplastic tumors and degenerative conditions of the spine, followed by vascular and autoimmune disorders. ${ }^{4-8}$ The incidence of NTSCI varies with both age and sex; it is more frequent in males and the incidence increases with age. ${ }^{9}$ The incidence of NTSCI is expected to increase and may overtake that of TSCI in the coming decades. ${ }^{10-12}$ The costs associated with NTSCI tend to be lower than those of TSCI largely because of the age of onset. NTSCI typically affects older patients. This population incurs fewer indirect costs over their remaining life span, primarily because they are no longer in the workforce. ${ }^{13,14}$ To implement appropriate prevention strategies, it is essential to have an idea of the extent of the problem in terms of etiology, demographics and extent of disability. ${ }^{15}$ To the best of our knowledge, there is a lack of information regarding epidemiologic data associated with SCI in Latin America. The aim of this study is to describe the clinical and demographic data of SCI in a tertiary care orthopedic hospital in Latin America.

\section{MATERIALS AND METHODS}

This is a retrospective study conducted from January of 2005 to December of 2012 in a tertiary orthopedic referral center. Patients with a diagnosis of SCI were admitted or referred to the services of spinal surgery and rehabilitation for spinal cord injury patients. A total of 585 patients were included in the study period, of these 152 were excluded because of incomplete patient data (129 patients), neurologic sequelae for previous cerebrovascular disease (19 patients) or associated lesions were below the L2 level (4 patients). Data were recorded on a special form and were recollected by trained spinal surgery fellows. Clinical interviews and physical examinations were made in the first $48 \mathrm{~h}$ following admission.

The variables studied were associated with the social demographic profile of patients (name, age, sex, marital status, personal income and occupation). In addition, the cause, type and level of injury were determined by physical examinations. Neurological levels of SCI were classified using the American Spinal Injury Association Impairment Scale (AIS). AIS A indicates a complete SCI lesion, with the loss of motor or sensory function in the lowest sacral

${ }^{1}$ Spine Surgery Service, National Rehabilitation Institute, Distrito Federal, México and ${ }^{2}$ Special Surgery Division, National Rehabilitation Institute, Distrito Federal, México Correspondence: Dr B Zárate-Kalfópulos, Spine Surgery Service, National Rehabilitation Insitute, Avenida México, Xochimilco \#289 Col., Arenal de Guadalupe, México Distrito Federal, Distrito Federal 14389, México.

E-mail: bzarate@inr.gob.mx or baronzk@hotmail.com

Received 19 August 2015; revised 16 February 2016; accepted 28 February 2016; published online 12 April 2016 
segment S2-S5. AIS B indicates an incomplete sensory lesion without motor function below the neurological level but with sensory function below the neurological level in S4-S5. AIS C indicates an incomplete motor lesion with motor function preserved below the neurological level, and more than half of the key muscle groups below the neurologic level have a muscle grade of $<3$. AIS D indicates an incomplete motor lesion in which motor function is preserved below the neurological level and at least half of the key muscle groups below the neurological level have a muscle grade of 3 and AIS E, where sensory and motor function is normal. ${ }^{16}$ Approval from the ethics committee of the National Rehabilitation Center was obtained for this study.

Descriptive statistics were used to represent data as average, range, median and percentages. Independent sample $t$-tests were used to compare parametric variables. Statistical analyses were performed using SPSS software (version 11.0, SPSS Inc, Chicago, IL, USA). A $P$-value of $<0.05$ was considered significant.

\section{RESULTS}

From a total of 433 patients admitted with a diagnosis of SCI during the study period, 346 TSCI and 87 had NTSCI. The proportion of TSCI and NTSCI in our center was 79.9 and $20.1 \%$, respectively.

In the TSCI group, 286 patients $(82.7 \%)$ were male and $60(17.3 \%)$ were female. The mean age was 33.9 years (range 12 to 65 years). The age group most frequently affected was $20-29$ years $(35.8 \%)$, followed by $30-39$ years $(19.3 \%)$. With respect to education, 145 patients (50.6\%) had completed elementary school and 37 patients $(10.7 \%)$ had completed university studies. With respect to marital status, $35.5 \%$ of patients were married and $45.3 \%$ were single. Regarding employment status, unemployed patients made up the largest proportion of the study population (144 patients $(41.6 \%)$ ), followed by patients who were self-employed (66 patients, (19\%)).

Motor vehicle accidents were the main cause of TSCI in 150 patients (43.4\%), followed by falls $107(30.9 \%)$ and fire weapons 58 (16.8\%). Vehicle accidents were mainly traffic collisions for 143 (95.4\%) patients, and $7(4.6 \%)$ patients had been run over by a vehicle. The vehicles involved in these accidents were mainly cars (124 accidents $(82.7 \%)$ ) and motorcycles (16 accidents (10.6\%)).

Falls occurred from a height higher than $6 \mathrm{ft}$ for 96 patients (89\%). Falls were associated with recreational diving for 9 patients $(8.4 \%)$ and with a horse in 2 patients $(0.9 \%)$. Other causes of TSCI were direct person-to-person contusions in 29 patients (8.38\%), of these 26 were associated with violence and 3 were associated with sports practice (1 football, 1 soccer, 1 wrestling). Knife stab wound was the reason of TSCI in two patients $(0.57 \%)$.

The thoracic level was the most frequently affected region (178 patients $(51.4 \%)$ ), followed by the cervical level in 138 patients $(30.9 \%)$ and the lumbar in 30 patients $(8.6 \%)$.

Regarding neurological levels, 218 patients (63\%) had paraplegia/ paraparesis and $128(36.9 \%)$ had quadriplegia/quadriparesis.

Lesions were classified using the AIS scale. In total, $62.7 \%$ of lesions were AIS A (complete), $13.8 \%$ were AIS B (sensory incomplete), $13.8 \%$ were AIS C (motor incomplete) and $9.5 \%$ were AIS D (motor incomplete).

In the NTSCI group, 48 patients (55\%) were male and $39(45 \%)$ were female. The mean age was 45.2 years (range $6-84$ years). The age group most frequently affected in NTSCI patients was 51-60 years (19.5\%), followed by $41-50$ years $(18.4 \%)$. In total, 62 patients $(71.3 \%)$ had completed elementary school, and only 6 patients $(6.9 \%)$ had completed university studies. Regarding marital status, $42.5 \%$ of patients were married and $29 \%$ were single. With respect to employment status, unemployed patients made up the largest proportion of the study population (31 patients $(35.6 \%)$ ), and 18 patients (20.8\%) were self-employed.
Table 1 Etiology of patients with traumatic and non-traumatic spinal cord injury

\begin{tabular}{lc}
\hline Characteristic & Patients, $\mathrm{n}(\%)$ \\
\hline Motor vehicle accident & $150(43.4)$ \\
Falls & $107(30.9)$ \\
Fire weapons & $58(16.8)$ \\
Direct person-to-person contusions & $29(8.38)$ \\
Knife stab wound & $2(0.57)$ \\
Tumor related & $50(57.4)$ \\
Degenerative disease & $17(19.5)$ \\
Inflamation & $9(10.3)$ \\
Infection & $7(8)$ \\
Vascular & $2(2.29)$ \\
Undetermined & $2(2.29)$ \\
\hline
\end{tabular}

Table 2 Severity and neurological clinical presentations of $\mathrm{TSCl}$ and NTSCI

\begin{tabular}{lcc}
\hline Grade & TSCI Patients, n (\%) & NTSCI Patients, n (\%) \\
\hline AIS A & $217(62.7)$ & $21(24.13)$ \\
AIS B & $48(13.9)$ & $17(19.54)$ \\
AIS C & $48(13.9)$ & $13(14.94)$ \\
AIS D & $33(9.5)$ & $36(41.33)$ \\
Paraplegia & $218(63)$ & $62(71.3)$ \\
Tetraplegia & $128(36.9)$ & $25(28.7)$
\end{tabular}

Abbreviations: AIS, American Spinal Injury Association Impairment Scale; NTSCI, non-traumatic spinal cord injury; TSCl, traumatic spinal cord injury.

Tumoral cord compression was the main cause of NTSCI in 50 patients $(57.4 \%)$. Lesions were classified as metastatic spinal tumors in 47 of these patients (94\%) and as primary bone tumors in 3 patients (6\%). The second most frequent etiology of NTSCI was myelopathy brought on by cervical or thoracic degenerative disease in 17 patients (19.5\%). Of the remaining $20.5 \%$ of patients with NTSCI, etiology was associated with inflammatory-infectious and vascular causes, including transverse myelitis in 9 patients (10.3\%), vertebral osteomyelitis in 7 patients (8\%) and arteriovenous malformations in 2 patients $(2.29 \%)$. Undetermined cases were reported in 2 patients $(2.29 \%$; see Table 1 )

The thoracic level was the most frequently affected region in 62 patients $(71.3 \%)$, followed by the cervical level in 24 patients $(27.5 \%)$. Only 1 patient $(1.1 \%)$ was affected at the L1 level. On the basis of neurological levels, paraplegia/paraparesis was the most common clinical presentation (62 patients $(71.3 \%)$ ), followed by tetraplegia/ tetraparesis (25 patients $(28.7 \%)$ ).

The lesions were classified using AIS. Lesions were classified as AIS $\mathrm{D}$ (motor incomplete) in $41.33 \%$, AIS C (motor incomplete) in $14.94 \%$, AIS B (sensory incomplete) in $19.54 \%$ and AIS A (complete) in $24.13 \%$ of patients.

Significantly, more males were affected with TSCI (286 patients $(82.7 \%)$ ) than with NTSCI (48 patients $(55 \%) ; P=0.002)$. Patients with NTSCI were significantly older ( 45.2 vs 33.9 years $(P=001))$. The proportion of patients with complete SCI (AIS A) was significantly higher in the TSCI group (62.7 vs $24.13 \%(P=0.0001))$ as expected, and the proportion of patients with AIS D was significantly higher in the NTSCI group (41.33 vs $9.5 \%(P=0.0001)$; see Table 2$)$. On the basis of occupation, most of the patients were unemployed at the time of the injury in both groups, but the proportion was significantly higher in the NTSCI group (72.4 vs $41.6 \%(P=0.0002)$ ). 


\section{DISCUSSION}

Understanding the factors that contribute to SCIs is paramount to injury prevention. ${ }^{17}$ Within the SCI population, TSCI accounts for the largest proportion of cases, and there are many publications describing the demographic data, etiology, neurological deficit, functional outcomes and disability of TSCI.

The three most common causes of TSCI are transportation accidents (road traffic crashes), falls and violence. In the African region, transportation accounts for $70 \%$ of cases, ${ }^{17}$ and in Denmark transportation-related injuries accounted for $56.9 \%{ }^{18}$ in a 22 -year period. In our study, 151 patients $(41.3 \%)$ were injured in a motor vehicle accident. This is less than previously reported; we believe this is due to the low average drive speed in México City, principally because of traffic congestion areas. Falls are the second leading cause of traumatic TSCI in our study, which was reported in 107 patients $(30.9 \%)$. This number is consistent with previous reports from Denmark $(35.5 \%),{ }^{18}$ the Eastern Mediterranean and Southeast Asia regions (40\%). ${ }^{19}$ In a study of 2716 cases of SCI in an Indian State, Mathur et al. ${ }^{20}$ found that $53 \%$ of patients had a fall from height, making this the principal cause of SCI in their study. Measures such as preventive programs in work specially for construction workers, side walls of stairs, education about the risks of diving in pools and climbing in trees may reduce the incidence SCI. Violence is the third most common cause of TSCI. In our study, fire weapons were associated with $16.8 \%$ of lesions, which is lower than the percentage previously reported in Brazil (42\%), ${ }^{21}$ Turkey $(25 \%)^{22}$ and South Africa $(21 \%)^{17}$ but higher than previously reported in the USA $(11.7 \%),{ }^{23}$ Western Europe $(4 \%)^{24}$ and Canada (2\%). ${ }^{25}$ On the basis of the epidemiological data from US National Spinal Cord Injury Statistical Database, the prevalence of NTSCI is between 25 and $60 \%{ }^{18,22,26-28}$ More recently, literature revealed a more accurate report of $23 \%,{ }^{29}$ consistent with the reported proportion of patients with NTSCI $(20.9 \%)$ in our study. Similar to what was previously reported in our study, the male:female patient ratio was relatively balanced (55 vs $45 \%$ ). ${ }^{29}$ The average age of individuals with TSCI was 31 years. In studies comparing TSCI and NTSCI patients, it was shown that individuals with NTSCI were significantly older. ${ }^{30}$ In our study, the mean age of patients with NTSCI was 45.2 years. Previous epidemiologic data also indicate results consistent with ours in which there was a greater number of non-working and retired patients (52.4\%) with NTSCI. ${ }^{18,31}$ We found that most patients with NTSCI were unemployed (31 patients $(35.6 \%)$ ) or dedicated to household activities (32 patients $(36.8 \%)$ ). It has been reported in the literature that NTSCI tends to be associated with more incomplete injuries. ${ }^{22}$ The number of cases with incomplete injuries as assessed by AIS scale scores in our study was also higher $(75.8 \%)$. Such incomplete injuries are potentially reversible; therefore, early detection and treatment are essential for these injuries.

In our study, the male:female ratio was well-balanced in patients with NTSCI ( 55 vs $45 \%$ ); however, in the TSCI group, the number of males affected was higher ( 82.7 vs $17.3 \%)$. Similar results were previously reported in which TSCI was higher in males and the male:female ratio was well balanced, similar to the NTSCI group. ${ }^{32}$

Paraplegia/paraparesis and tetraplegia/tetraparesis are the most frequent presentation in both the TSCI (63 vs 36.9\%) and NTSCI (71.3 vs $28.7 \%$ ) groups. ${ }^{29}$ In addition, we reported here that $71.3 \%$ of injuries in the NTSCI group occurred in the thoracic region. This result can be explained by the fact that tumoral cord compression is typically observed in the thoracic region (including in primary and metastatic spinal tumors) and is a frequent etiologic factor. These findings are consistent with what have previously been reported in the literature. ${ }^{28,30,31,33}$

The proportion of patients with TSCI and NTSCI was similar to what was previously reported by $\operatorname{Cosar}^{5}$ et al. in a study of 165 patients over 12 years, which reported 23\% of patients had NTSCI and 77\% had TSCI. The author also reported that significantly higher age [53.97 years vs 37.8 years, respectively $(P<0.05)$ ] was associated with incomplete SCI vs NTSCI. This result was consistent with our findings that, in the NTSCI group, the proportion of patients was significantly lower $(20.1$ vs $79.9 \%(P=0.0001)$ ), age was higher ( 53.9 years vs 37.8 years $(P<0.002))$ and SCI was less severe (AIS D 41.33 vs $9.5 \%$ $(P=0.0001))$ in comparison with the TSCI group.

One of the limitations of this study is that data for only one tertiary care hospital were obtained. Therefore, our data are not necessarily representative of the entire country. Epidemiological data from both TSCI and NTSCI are needed to increase the allocation of health-care resources in the field of spinal surgery and rehabilitation care and to establish appropriate management programs for this chronic condition.

Because of trends in growing life expectancy it is anticipated that future studies will demonstrate a significant increase in the incidence of NTSCI in the coming decades. This knowledge can help facilitate health-care planning, specifically in the case of developing countries.

\section{CONCLUSIONS}

On the basis of the present findings, the demographic profile of patients with traumatic and non-traumatic SCI was significantly different in terms of age, male:female ratio and incomplete vs complete injury.

TSCI has a male predominance, and motor vehicle accident is the most frequent cause of injury. Males are also most frequently affected my NTSCI, and tumoral cord compression is the main cause.

Incomplete SCI is most frequent in NTSCI patients. Such incomplete injuries are potentially reversible; therefore, early detection and treatment are essential.

\section{DATA ARCHIVING}

There were no data to deposit.

\section{CONFLICT OF INTEREST}

The authors declare no conflict of interest.

1 Sekhon LH, Fehlings MG. Epidemiology demographics, and pathopysiology of acute spinal cord injury. Spine 2001; 26: S2-12.

2 McKinley WO, Seel RT, Gadi RK, Tewksbury MA. Nontraumatic vs traumatic spinal cord injury: a rehabilitation outcome comparison. Am J Phys Med Rehabil 2001; 80: 693-699.

3 Majdan M, Brazinova A, Mauritz W. Epidemiology of traumatic spinal cord injuries in Austria 2002-2012. Eur Spine J 2015; 25: 62-73.

4 Löfvenmark I, Norrbrink C, Nilsson-Wikmar L, Hultling C, Chakamdinakira S, Hasselberg M. Traumatic spinal cord injury in Botswana: characteristics, aetiology and mortality. Spinal Cord 2015; 53: 150-154.

5 Wyndaele M, Wyndaele J-J. Incidence, prevalence and epidemiology of spinal cord injury: what learns a worldwide literature survey? Spinal Cord 2006; 44: 523-529.

6 New PW, Cripps RA, Bonne Lee B. Global maps of non-traumatic spinal cord injury epidemiology: towards a living data repository. Spinal Cord 2014; 52: 97-109.

7 New PW, Sundararajan V. Incidence of non-traumatic spinal cord injury in Victoria, Australia: a populationbased study and literature review. Spinal Cord 2008; 46: 406-411.

8 McKinley MO, Tewksbury MA, Goodbout CJ. Comparision of medial complications following nontraumatic and traumatic spinal cord injury. J Spinal Cord Med 2002; 25: 88-93.

9 Noonan VK, Fingas M, Farry A, Baxter D, Singh A, Fehlings MG et al. Incidence and prevalence of spinal cord injury in Canda: a national prespective. Neuroepidemiology 2012; 38: 219-226. 
10 New PW, Farry A, Baxter D, Noonan VK. Prevalence of non-traumatic spinal cord injury in Victoria, Australia. Spinal Cord 2013; 51: 99-102.

11 García-Estévez DA, Miguéns-Vázquez X, Cadarso-Palau A, Quevedo-Vila V. Nontraumatic myelopathies in a district hospital: an epidemiological descriptive study of 68 cases. Rev Neurol 2013; 57: 383-384.

12 Quintana-González A, Sotomayor-Espichain R, Martínez-Romero M, Kuroki-García C. Lesiones medulares no traumáticas: Etiología, demografía y clínica. Rev Peru Med Exp Salud Publica 2011; 28: 633-638.

13 Ferdiana A, Post MW, Hoekstra T, van der Woude LH, van der Klink JJ, Bültmann U. Employment trajectories after spinal cord injury: results from a 5-year prospective cohort study. Arch Phys Med Rehabil 2014; 95: 2046.

14 Krause JS, Bozard JL. Natural course of life changes after spinal cord injury: a 35-year longitudinal study. Spinal Cord 2012; 50: 227-231.

15 Ibrahim A, Lee KY, Kanoo LL, Tan CH, Hamid MA, Hamedon NM et al. Epidemiology of spinal cord injury in hospital Kuala Lumpur. Spine 2013; 38: 419-424.

16 Kirshblum SC, Biering-Sorensen F, Betz R, Burns S, Donovan W, Graves DE et al. International standards for neurological classification of spinal cord injury: cases with classification challenges. J Spinal Cord Med 2014; 37: 120-127.

17 Fielingsdorf K, Dunn RN. Cervical spine injury outcome-a review of 101 cases treated in a tertiary referral unit. S Afr Med J 2007; 97: 203-207.

18 Bjornshave Noe B, Mikkelsen EM, Hansen RM, Thygesen M, Hagen EM. Incidence of traumatic spinal cord injury in Denmark 1990-2012: a hospital-based study. Spinal Cord 2015; 53: 436-440.

19 Alshahari SS, Cripps RA, Lee BB, Al-Jadid MS. Traumatic spinal cord injury in Saud Arabia: an epidemiological estimate from Riyadh. Spinal Cord 2012; 50: 882-884.

20 Mathur N, Jain S, Kumar N, Srivastava A, Purohit N, Patni A. Spinal cord injury: scenario in an Indian state. Spinal Cord 2015; 53: 349-352.

21 Costacurta ML, Taricco LD, Kobaiyashi ET, Cristante AR. Epidemiological profile of a pediatric population with acquired spinal cord injury from AACD: Sao Paulo/Brazil. Spinal Cord 2010; 48: 118-121.
22 Ones K, Yilmaz E, Beydogan A, Gultekin O, Caglar N. Comparison of functional results in non-traumatic and traumatic spinal cord injury. Disabil Rehabil 2007; 29 1185-1191.

23 DeVivo MJ, Chen Y. Trends in new injuries prevalent cases, and aging with spinal cord injury. Arch Phys Med Rehabil 2011; 92: 332-338.

24 Scivloetto G, Farchi S, Laurenza L, Molinari M. Traumatic and non-traumatic spinal cord lesions: an Italian comparison of neurological and functional outcomes. Spinal Cord 2011; 49: 391-396.

25 O'Connor P. Incidence and patterns of spinal cord injury in Australia. Accid Anal Prev 2002; 34: 405-415.

26 Chung SB, Lee SH, Kim ES, Eoh W. Incidence of deep vein trombosis after spinal cord injury: a prospective study in 37 consecutive patients with traumatic or nontraumatic spinal cord injury treated by mechanical prophylaxis. J trauma 2011; 71: 867-871.

27 Rouleau P, Guertin PA. Traumatic and non traumatic spinal cord injured patients in Quebec Canada. Part 2: Biomech Profile 2010; 48: 819-824.

28 New PW, Rawicki HB, Bailey MJ. Nontraumatic spinal cord injury: demographic characteristics and complications. Arch Phys Med Rehabil 2002; 83: 996-1001.

29 Cosar SN, Yemisci OU, Oztop P, Cetin N, Sarifakioglu B, Yalbuzdag SA et al. Demographic characteristics after traumatic and non-traumatic spinal cord injury: a retrospective comparison study. Spinal Cord 2010; 48: 862-866.

30 Celani MG, Spizzichino L, Ricci S, Zampolini M, Franceschini M. Spinal cord injury in Italy: a multicenter retrospective study. Arch Phys Med Rehabil 2001; 82: 589-596.

31 Bransford RJ, Chapman JR, Skely AC, VanAlstyne EM. What do we currently know about thoracic apinal cord injury recovery and outcomes? A systematic review. J Neurosurg Spine 2012; 17: 52-64.

32 Scivoletto G, Lapenna LM, Di Donna V, Laurenza L, Sterzi S, Foti C et al. Neoplastic myelopathies and traumatic spinal cord lesions:an Italian comparision of functional and neurological otucomes. Spinal Cord 2011; 49: 799-805.

33 Vervoordeldonk JJ, Post MW, New P. Rheabilitation of patients with traumatic spinal cord injury in the Netherlands: etiology, length of stay and functional outcome. Top Spinal Cord Inj Rehabil 2013; 19: 195-201. 